\title{
State support to medication therapy for children in Latvia
}

D. Araja

Rīga Stradiņš University, Riga, Latvia

\begin{abstract}
On global and European scale, maternal and child's health is proposed as one of the top-priority indicator of public health and welfare. In general, national welfare, social development and health are characterised by the birth and infant mortality rates. Having evaluated these indicators, it may be concluded that in Latvia since 2012 the birth rate is increasing from year to year, whereas the infant mortality rate is gradually decreasing verging on the average rate of the European Union member states in 2014. The birth rate depends very heavily on the country's economic situation within a specific period of time and the parents' readiness to undertake child rearing, whereas the infant mortality rate is more connected with the maternal and child health condition as well as the availability of health care in the country. This Research analyses national policy instruments for the enhancement of maternal and child health in the last three years paying special attention to the state support to medication therapy for children in Latvia, taking into consideration that medicinal products constitute a significant element of health technologies. The results show possible correlation between application of state support instruments and improvement of child health indicators. The most important measures ensuring state support to medication therapy for children in Latvia are reimbursement of the purchase of medicinal products and medical devices intended for outpatient treatment, centralised purchasing of medicinal products performed by the National Health Service and medicinal establishments as well as a specific budget sub-programme designed for the treatment of children with rare diseases.
\end{abstract}

\section{Introduction}

On a global and European scale, maternal and child health is proposed as one of the toppriority indicator of public health and welfare. For the development of the maternal and child health sector, a number of the global and European level strategic documents and guidelines have been elaborated (Global Strategy for Women's and Children's Health [1]; European Strategy for Child and Adolescent Health Development [2] etc.). Facilitation of maternal and child health contributes not only to the reproductive and child health but also improves public health in general. A healthy child is a precondition for a healthy society. Child health and development until birth and in the first year of life mainly depends on the mother's and father's health, lifestyle, habits, their knowledge about child health and childcare. The Population and Housing Census approves that economic migration and low fertility has led to population ageing in Latvia. On 1 January 2011 the average age was 41.6 years -6 moths more than the average age published earlier [3].

The aim of the Research is to analyse political initiatives implemented in health care which are focused on the improvement of child health, as well as the state resources allocated for medication therapy for children in Latvia and the impact thereof on the child health indicators.

(C) The Authors, published by EDP Sciences. This is an Open Access article distributed under the terms of the Creative Commons Attribution License 4.0 (http://creativecommons.org/licenses/by/4.0/). 


\section{Materials and methods}

The materials and methods used to meet the goal of the Research include the analysis of the data of policy planning documents, regulatory enactments and state budget as well as the use of statistical information prepared by competent institutions to determine the trends of public funding and their relation to the changes in health care indicators.

\section{Results}

Promoting good health is an integral part of Europe 2020, the European Union's 10year economic-growth strategy [4]. In accordance with the Declaration on the Intended Activities of the Cabinet of Ministers of Latvia (Chapter II - Quality of Life of a Family and an Individual in Latvia) in order to improve well-being of the families and secure the reproduction of the nation, the aim and challenge for the next four years is to reduce social and income inequality. The Cabinet of Ministers will work to ensure that everyone, especially people with low income and families with children, has the opportunity, by performing decent work, to earn the income necessary for obtaining high quality education, to access health care and social services, where necessary, as well as to enjoy the culture events. The Cabinet of Ministers believes that it is the way how to ensure social security in the country and promote the people's participation in activities of the communities and civil society thus providing opportunities for having life full of pride and satisfaction in united and patriotic country, which is aware of its national identity and is rooted in the common values of all inhabitants of Latvia [5].

In Latvia, the Maternal and Child Health Improvement Plan 2012-2014 [6] has been developed in accordance with the goal of the United Nations (UN) to reduce child mortality and improve maternal health [7]. Each UN member state chooses targets relevant to local circumstances by developing aims, objectives and indicators appropriate for them and following their progress in the achievement of results.

Infant mortality is one of the indicators which characterises the general state of health of both mother and child, as well as the health care before and after delivery, and indirectly characterises the socio-economical circumstances in the country in general. The leading causes of infant death are certain conditions originating in the perinatal period. Said conditions are a cause of death in approximately $50 \%$ of infants of all infants who died in the first year of their life (see Fig. 1).

Congenital anomalies are the cause of death in nearly one fourth of infants who died in the first year of their life. Over the last years, this indicator has demonstrated a tendency towards decrease. It may be explained by genetic tests done in a timely fashion as a result of which it was possible to diagnose congenital pathologies and terminate pregnancy thus reducing the risk of birth of critically ill children; however, in the majority of cases a pathology is lately diagnosed, pregnancy is terminated after 22 weeks and such cases are included in the perinatal mortality rate. The number of congenital abnormalities is still high which proves that it is essential to introduce additional ultrasound examination and improve perinatal diagnosis of congenital abnormalities which would make it possible to reveal congenital pathologies more precisely, prepare for them or terminate pregnancy in the event of such pathologies when severe long-term effects are predicted after their prevention.

Therefore, the Maternal and Child Health Improvement Plan envisages a package of measures aimed to improve health of both mother and child, facilitate birth rate and reduce the number of cases of infant and child sickness and mortality, and has become one of the most essential instruments for the enhancement of medication therapy for children. 


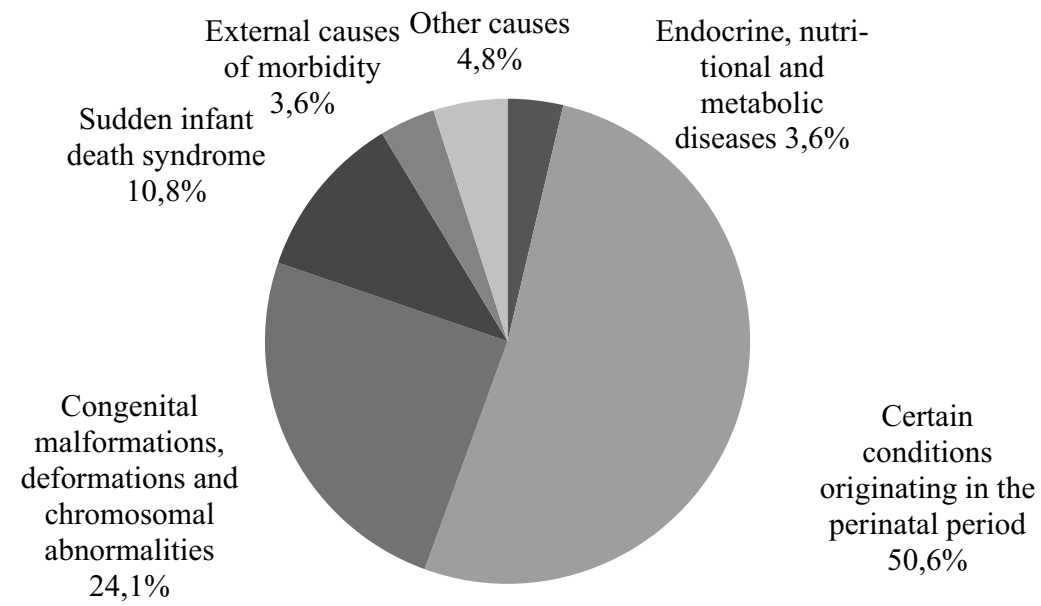

Figure 1. The leading causes of infant death in Latvia, 2014 [8].

In general it should be noted, that the State support to medication therapy for children in Latvia is realised by the following State budget sub-programmes:

- Payment for reimbursable medicinal products and medical devices

- Maternal and Child Health Improvement Plan

- Centralised procurement of medicinal products and materials

- Medical treatment of children's rare diseases.

\section{Payment for reimbursable medicinal products and medical devices}

The procedures for reimbursement of expenditures for the acquisition of medicinal products and medical devices intended for out-patient medical treatment (hereinafter - the procedures for reimbursement) are a set of measures, which provides a patient with an opportunity to acquire medicinal products and medical devices, the expenditures for the acquisition of which are completely or partially covered by the funds from the State budget for the current year granted for the reimbursement of expenditures for the acquisition of medicinal products and medical devices. The purpose of measures included in the procedures for reimbursement is to ensure medicinal products and medical devices necessary for as wide range of patients as possible within the framework of funds granted for reimbursement, as well as to achieve the lowest possible price of reimbursable medicinal products and medical devices within the framework of procedures for reimbursement, and to direct the resources obtained as a result of saving for the ensuring of needs of patients within the framework of the procedures for reimbursement.

Expenditures for the acquisition of reimbursable medicinal products shall be covered, applying the following reimbursement categories [9]:

- Category I - reimbursement in the amount of $100 \%$ or in the amount of the reference price of the relevant group (in respect of medicinal products and medical devices included on List A of reimbursable medicinal products), if it has been determined that a patient has a chronic, life-threatening disease or a disease, which 


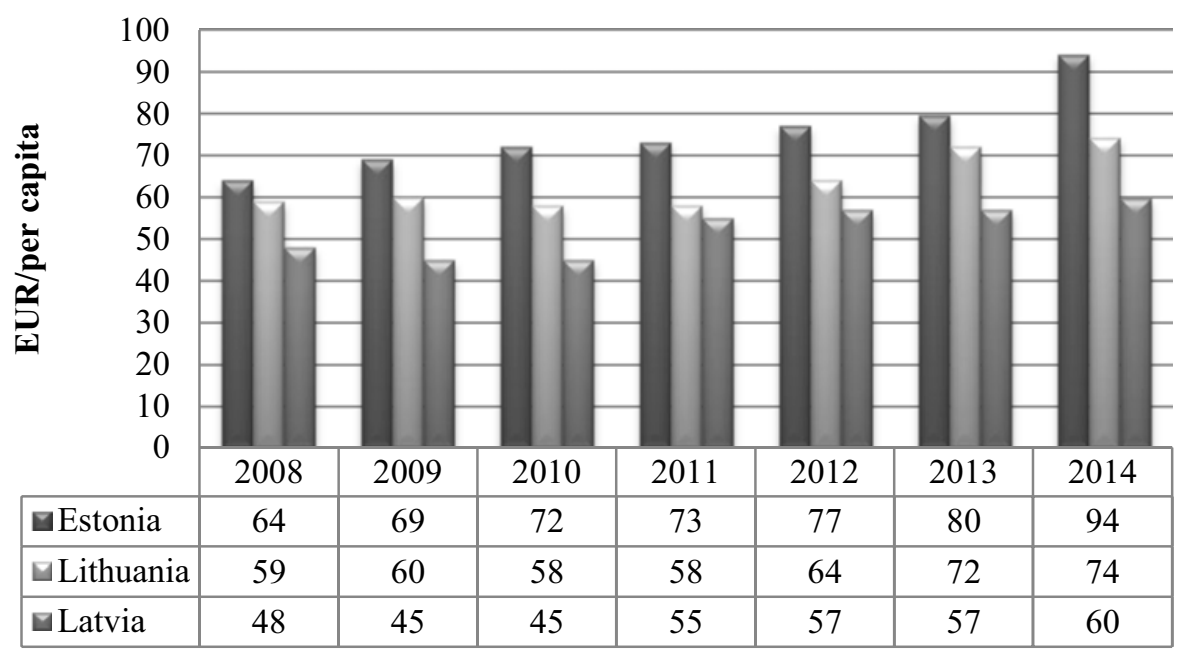

Figure 2. State budget resources allocated for the reimbursement of expenditures for the acquisition of medicinal products and medical devices intended for out-patient medical treatment in Estonia, Latvia and Lithuania, 2008-2014 [10].

causes serious irreversible disability and the medical treatment of which requires the use of the respective medicinal products in order to maintain the patient's vital functions;

- Category II - reimbursement in the amount of $75 \%$ or - in respect of medicinal products and medical devices included on List A of reimbursable products - in the amount of $75 \%$ of the reference price of the relevant group, if it has been determined that a patient has a chronic disease, in the medical treatment of which the maintenance of the patient's vital functions is made difficult or which causes serious disability without the use of the respective medicinal products; and

- Category III - reimbursement in the amount of 50\% or - in respect of medicinal products and medical devices included on List A of reimbursable products - in the amount of $75 \%$ of the reference price of the relevant group, if it has been determined that a patient has a chronic or acute disease, in the medical treatment of which the use of the respective medicinal products is necessary in order to maintain or improve the patient's state of health or in case where vaccines are paid for from the funds granted for reimbursement.

Regardless of the fact that the reimbursement procedure in Latvia is developing under the circumstances of strictly limited financial resources and the amount of the allocated state budget funds is obviously lower not only than the average European Union indicators but also than those of the neighbouring Baltic states (see Fig. 2), in 2012, within the framework of the Maternal and Child Health Improvement Plan, a number of additional measures to facilitate the availability of medicinal products for the improvement of child health were envisaged.

\section{Maternal and Child Health Improvement Plan}

Substantial work has been launched in 2012 for implementation of the activities of the Maternal and Child Health Improvement Plan, 2012-2014. Contracts have been concluded for execution of the State-funded medical fertilization, expanded range of the State-funded 
maternity care providers, by providing opportunities for women to receive the pregnancy surveillance at specialists, having previously provided only paid health care services.

The Maternal and Child Health Improvement Plan has included the following activities in context of medication therapy:

- since August, 2012 - reimbursement of the vaccination against flu for pregnant women in the amount of $50 \%$;

- since September 1, 2012 - reimbursement of the expenditures for the acquisition of prescription medicinal products, which are not included in the List of Reimbursed Medicines, but used for treatment of pregnant women, women in the post-natal period up to 42 days (in the amount of $25 \%$ ) and children up to 24 months of age (in the amount of 50\%). In accordance with the Health National Service's data 5015 children have received the reimbursement (in amount of 39160.46 euro) in scope of this activity in 2012, as well as 20329 children (in amount of 312901.43 euro) - in 2013, and 28764 (in amount of 474548.49 euro) - in 2014 [11];

- since November 1, 2012 - additional diagnoses are included at the procedures for reimbursement in the amount of $100 \%$ (Z31.1 Artificial insemination; Z31.2 In vitro fertilization; N46 Male infertility; N97 Female infertility);

- since January 1, 2014 - reimbursement of the expenditures for the acquisition the medicinal products included in the List of Reimbursed Medicines, which are reimbursed in according to the general procedures, to children until they are 18 years old in the amount of $100 \%$.

The Maternal and Child Health Improvement Plan was developed for 2012-2014 but the measures envisaged therein will be continued in the following years as well, including within the framework of the reimbursement procedure; in addition, new measures are being implemented, i.e. as of 01 June 2015 in case of acute respiratory infections the medicinal products included in the List of Reimbursed Medicines are now fully reimbursed (in the amount of 100\%) to children until they are 18 years old instead of 3 years old as it used to be before.

\section{Centralised procurement of medicinal products and materials}

Resources of the State budget sub-programme 'Centralised procurement of medicines and materials' are provided for centralised procurement of medicines, medical devices and specialised products, which has been performed by the National Health Service as the commissioning party and the payer for the procurements: vaccine, syringes, standard tuberculin, peritoneal dialysis medicines, phenylketonuria adjustment preparations and medical nutrition products, vision adjustment means for child. The available resources of this sub-programme were 10639180 euro in 2013, and the same amount - in 2014 [12].

\section{Medical treatment of children's rare diseases}

Funds of the State budget sub-programme 'Medical treatment of children's rare diseases' is being provided for medical treatment of children suffering from rare diseases registered with the Children's Clinical University Hospital (Gaucher disease, mucopolysaccharidosis, homocystinuria etc.), ensuring the maintenance of vitally important life functions. In European Union, a disease is considered to be rare if it has affected no more than five from 10 thousand people. The available resources of this sub-programme were 987206 euro in 2013, and 1302702 euro - in 2014 [12]. 


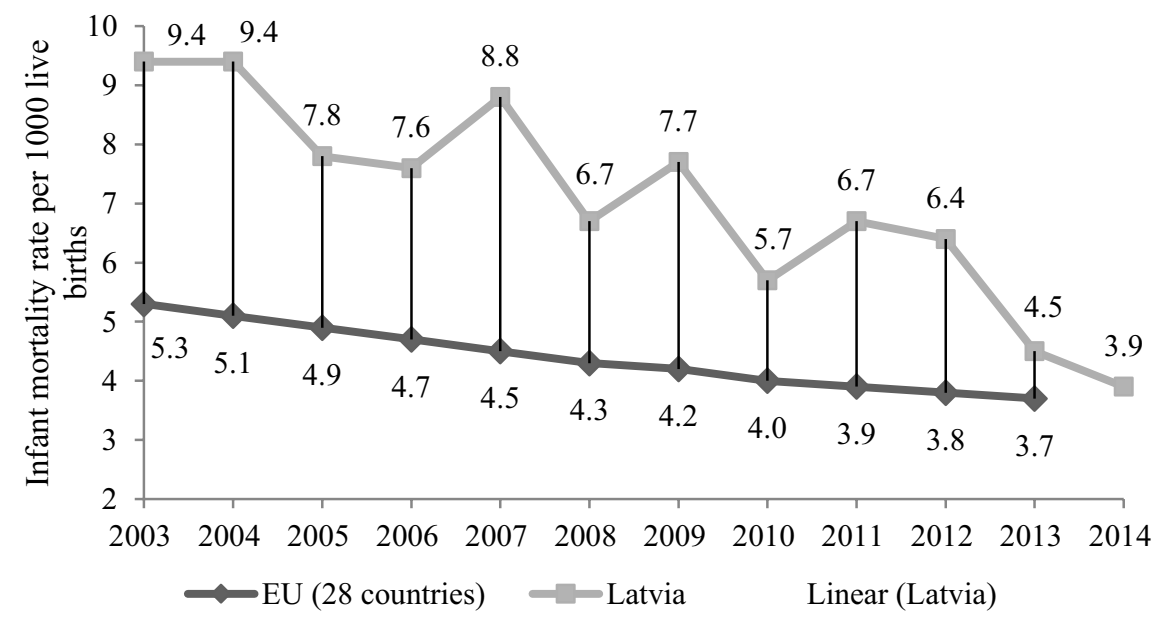

Figure 3. Infant mortality rate per 1000 live births, European Union's average and Latvia, 2003-2014 [13, 14].

\section{Discussion}

Analysing the measures for the maternal and child health improvement taken by the State in the period starting from 2012 as well as the respective statistical data which certify, inter alia, about a tendency of steady decrease in the infant mortality rate (see Fig. 3) which in 2014 verged the European Union's average, it may be assumed that there is positive correlation between the policy implemented by the State and the respective statistical data.

According to the information summarised by National Health Service, in comparison with 2013, funding for the provision of child health care services in 2014 grew by 6 mln euro. Last year, the State paid almost $86 \mathrm{mln}$ euro for the inpatient and outpatient services rendered to children [15].

The amount of State funds spent on reimbursement for medicinal products for children also increased having achieved $9 \mathrm{mln}$ euro in 2014 (in $2013-6.7 \mathrm{~min}$ ). Such increase may be explained by the changes in the reimbursement regulations. From the beginning of 2014, the medicinal products included in the List of Reimbursed Medicines are reimbursed 100\% to the patients aged under 18 . National Health Service regularly reviews the prices of medicinal products included in the List of Reimbursed Medicines which ensures that more patients receive medicinal products.

Last year, the State paid $2.4 \mathrm{mln}$ euro for health care provided to children abroad of which nearly 2 mln euro were paid for cases when a State-paid health care service could not be provided in Latvia but it was necessary to prevent irreversible worsening in a child's vital functions or state of health.

Many steps have been taken to ensure that rare disease patients get full-fledged health care. In 2015, the State started paying for medical foods intended for children registered with the palliative care consulting room and patients of the cystic fibrosis consulting room of the Children's Clinical University Hospital. Changes in the regulatory enactments have also been made to ensure that the patients of the Children's Clinical University Hospital receive medication therapy for rare diseases also after they have turned 18. Last year, the State paid $1.5 \mathrm{mln}$ euro for the rare disease medication therapy.

Another important aspect in child health care is changes in the immunisation schedule since in 2015 State-paid infant immunisation against rotavirus infection was started. 


\section{Conclusion}

Child health and development until birth and in the first year of life mainly depends on the mother's and father's health, lifestyle, habits, their knowledge about child health and childcare. A significant role in the improvement of the infant's life quality is played by educating society about the factors of infant mortality risks and measures for prevention thereof especially by educating the families with one child aged younger than 1. Further on in life, healthy nourishment and sufficient physical activity is important since it increases life expectancy, improves quality of life and reduces expenses of an individual, family and the State by virtue of disease prevention.

The lack of public financial resources poses a real challenge to the government, which should insure the accessibility and affordability of necessary health care services for the population. At recent years the government performed the important reforms prioritising primary care, services for children and pregnant women, as well as emergency assistance and medicines. The children's health is defined as one of the health care priorities in Latvia. The implemented measures have insured the significant improvement and optimisation of resources management but in the circumstances of the strictly limited state budget a necessity to use additional possibilities to optimise the resources allocation to the health care programmes and prevention activities remain topical.

\section{References}

[1] Global Strategy for Women's and Children's Health. United Nations Secretary-General (2010).

[2] European Strategy for Child and Adolescent Health Development. World Health Organisation (2005).

[3] Population and Housing Census 2011. Central Statistical Bureau. Online: http://www.csb.gov.lv/en/statistikas-temas/populationcensus-2011-key-indicators-33613.html

[4] Europe 2020 -a strategy for smart, sustainable and inclusive growth. European Commission. Online: http://eur-lex.europa.eu/LexUriServ/LexUriServ . do?uri=COM:2010:2020:FIN:EN:PDF.

[5] Declaration on the Intended Activities of the Cabinet of Ministers of Latvia. Online: http://www.mk.gov.lv/sites/default/files/editor/2014_11_04_ deklaracija_gala_red.pdf

[6] Maternal and Child Health Improvement Plan 2012-2014.Order No269 of the Cabinet of Ministers of Latvia. Online: http://likumi . lv/doc .php?id=249406.

[7] United Nations Millennium Declaration (2000). Online: http://www.un.org/ millennium/declaration/ares552e.pdf

[8] The leading causes of infant death in Latvia (2014). Centre for Disease Prevention and Control. Online: http://www.spkc.gov.1v/veselibas-aprupes-statistika/

[9] The procedures for reimbursement of expenditures for the acquisition of medicinal products and medical devices intended for out-patient medical treatment. Regulations No899 of the Cabinet of Ministers of Latvia. Online: http://likumi.lv/doc. php?id=147522.

[10] Public resources allocated for the reimbursement system of medicines and medical devices in Estonia, Latvia and Lithuania, 2008-2014. National Health Service (2015).

[11] Operative budget information. National Health Service (2015). Online: http:// www. vmnvd.gov. lv/lv/503-ligumpartneriem/operativa-budzetainformacija/arhivs 
[12] 22.Vēstis. National Health Service (2014). Online: http://www.vmnvd.gov . lv/uploads/files/54215cd72553c.pdf

[13] Infant mortality rate per 1000 live births, in Latvia. Centre for Disease Prevention and Control (2015). Online: http://www.spkc.gov.lv/veselibas-aprupesstatistika/

[14] Infant mortality rate per 1000 live births, EU (28 countries). Eurostat. Online: http://ec.europa.eu/eurostat/ tgm/table.do?tab =table\&init=1\& language $=$ en\&pcode $=$ tps00027\&plugin $=1$

[15] The State budget expenditures for children's treatment increase. National Health Service (2015). Online: http://www.vmnvd.gov.lv/lv/aktualitates/475pieaug-valsts-izdevumi-bernu-veselibas-aprupei 